PERSPECTIVES

\section{Unequal gains of function are a headache for migraine mechanisms}

\begin{abstract}
Osvaldo D. Uchitel
Institute of Physiology, Molecular Biology and Neuroscience, CONICET, Departamento de Fisiología, Biología Molecular y Celular, Facultad de Ciencias Exactas y Naturales, Universidad de Buenos Aires, Argentina
\end{abstract}

Email: odu@fbmc.fcen.uba.ar

Migraine is currently considered a common and complex brain disorder of neural excitability. Advances in migraine genetics have led to the identification of mutations in several genes associated with a rare form of migraine called familial hemiplegic migraine (FHM). The genes identified to date encode proteins that are involved in the control of brain excitability: FHM-1, the P/Q-type voltage-gated calcium channel; FHM-2 associated with the $\mathrm{Na}^{+} / \mathrm{K}^{+}$-ATPase; and FHM-3 linked to the voltage-gated sodium channel, SCN1A. Typical migraine attacks in FHM-1 patients are associated with transient hemiparesis, but apart from this, they are identical to those of the common forms of migraine with aura (Pietrobon, 2010). This makes FHM-1 a promising model to also study the pathogenic mechanisms of the common forms of migraine. FHM-1 mutations in the CACNA1A gene encoding the main $\alpha$ subunit of the $\mathrm{P} / \mathrm{Q}$ calcium channel produce a gain-of-function of human recombinant $\mathrm{Ca}_{\mathrm{V}} 2.1$ channels, mainly due to channel activation at lower voltages and increased channel open probability (Tottene et al. 2002; Pietrobon, 2010). A knock-in (KI) migraine mouse model carrying the human FHM-1 R192Q mutation has been generated (van den Maagdenberg et al. 2004) allowing the mutant channels to be studied in their native neuronal environment and at their endogenous level of expression. KI mice exhibit several gain-of-function effects and an increased propensity for cortical spreading depression (CSD) - a wave of cortical depolarization that has been strongly implicated in the generation of migraine aura (Ayata, 2009). CSD has also been implicated in sensitization of the trigeminal ganglia (TG) afferents innervating the meninges, a proposed mechanism underlying migraine headache (Olesen et al. 2009).

In a recent issue of The Journal of Physiology Fioretti et al. (2011) examined the P/Q-type calcium currents and the excitability properties of two defined subpopulations of small TG neurons in R192Q FHM-1 KI mice. The key finding of this study is the demonstration that the $\mathrm{Ca}_{\mathrm{V}} 2.1$ channels expressed in capsaicin-sensitive (CS) neurons and capsaicin-insensitive with T-type $\mathrm{Ca}^{2+}$ currents (CI-T) neurons are differently affected by the R192Q FHM-1 mutation. The activation of the P/Q-type calcium current was shifted to lower voltages and the P/Q-type calcium current density was larger in CI-T neurons from R192Q KI compared to WT mice. In contrast they show that the FHM-1 mutation does not affect the P/Q-type calcium currents expressed at the soma of the CS neurons. Altered properties of somatic P/Q-type calcium currents were reported from several neuronal types (van den Maagdenberg et al. 2004; Tottene et al. 2009) and at the brainstem calyx of Held presynaptic nerve terminal (Inchauspe et al. 2010) of this animal model. Accordingly, an increased probability of glutamate release at the excitatory synapses is observed but surprisingly, not at GABAergic inhibitory synapses of the cortex despite also being mediated by P/Q-type channels (Tottene et al. 2009). Similarly, (Fioretti et al. 2011) found that the release of calcitonin gene-related peptide (CGRP) from the dura is not affected, although the release from the ganglia is increased in this FHM-1 migraine mouse model. Thus, the expression of channels with unaltered activation properties could explain the unaltered release of CGRP at the dura or GABA at the inhibitory synapses. However, so far there is no information regarding the molecular composition of the $\mathrm{P} / \mathrm{Q}$ channels in terms of splice variants or types of auxiliary subunits and there is only indirect evidence regarding which type is present at the nerve terminal. In any case, the differential expression of the P/Q channels with altered properties is a novel observation that could explain the differential release of trans- mitter, and contribute together with other neuronal properties such as presynaptic nerve terminal action potential waveform (Inchauspe et al. 2010) to generate the imbalance of cortical excitation-inhibition observed in this animal model.

It is believed that activation of trigeminal neurons innervating the meninges and release of proinflammatory peptides (in particular CGRP) from their terminals play a key role in generating migraine pain (Pietrobon, 2010). In contrast, the lack of CI-T neuronal dural afferents and the unaltered release of dural CGRP leads the authors to postulate that facilitation of peripheral mechanisms of CGRP action, such as dural vasodilatation and peripheral dural nociceptor sensitization, does not contribute to the generation of headache in FHM-1. Furthermore, the increase of CGRP release at the TG ganglia supports the idea put forward by these authors that enhanced intraganglionic release of neurotransmitter from CI-T neurons is a $\mathrm{P} / \mathrm{Q}$ calcium gain-of-function and might enhance peripheral sensitization. Although this hypothesis is in line with their findings, the overall role of CGRP in eliciting migraine attack in FHM-1 patients has been recently challenged. Hansen et al. (2011) have shown that systemic application of CGRP induces migraine attacks in common migraine with and without aura but failed to trigger more migraine-like attacks in FHM patients. Thus, the relevance for headache mechanisms of enhanced intraganglionic release of CGRP or other vasoactive neuropeptides from neurons that do not innervate the dura remains to be established by future studies.

\section{References}

Ayata C (2009). Cephalalgia 29, 1095-1114.

Fioretti B, Catacuzzeno L, Sforna L, Gerke-Duncan MB, van den Maagdenberg AM, Franciolini F, Connor M \& Pietrobon D (2011). J Physiol 589, 5879-5896.

Hansen JM, Thomsen LL, Olesen J \& Ashina M (2011). Headache 51, 544-553.

Inchauspe CG, Urbano FJ, Di Guilmi MN,

Forsythe ID, Ferrari MD, van den

Maagdenberg AM \& Uchitel OD (2010).

J Neurophysiol 104, 291-299.

Olesen J, Burstein R, Ashina M \& Tfelt-Hansen P (2009). Lancet Neurol 8, 679-690. 
Pietrobon D (2010). J Physiol 588, 1871-1878.

Tottene A, Conti R, Fabbro A, Vecchia D,

Shapovalova M, Santello M et al. (2009).

Neuron 61, 762-773.
Tottene A, Fellin T, Pagnutti S, Luvisetto S, Striessnig J, Fletcher C \& Pietrobon D (2002). Proc Natl Acad Sci U S A 99, 13284-13289. van den Maagdenberg AM, Pietrobon D, Pizzorusso T, Kaja S, Broos LA, Cesetti T et al. (2004). Neuron 41, 701-710. 